\title{
Pattern of Medical Device Adverse Events in a Tertiary Level Hospital in Northern India: An Ambispective Study
}

\author{
Saifuddin PK \\ Post Graduate Institute of Medical Education and research,Chandigarh,India \\ Ajay Prakash \\ Post Graduate Institute of Medical Education and research,Chandigarh,India \\ Ram Samujh \\ Post Graduate Institute of Medical Education and research,Chandigarh,India \\ SK Gupta \\ Post Graduate Institute of Medical Education and research,Chandigarh,India \\ Vanita Suri \\ Post Graduate Institute of Medical Education and research,Chandigarh,India \\ Rohit Manoj Kumar \\ Post Graduate Institute of Medical Education and research,Chandigarh,India \\ Siddhartha Sharma \\ Post Graduate Institute of Medical Education and research,Chandigarh,India \\ Phulen Sarma \\ Post Graduate Institute of Medical Education and research,Chandigarh,India \\ Bikash Medhi ( $\sim$ drbikashus@yahoo.com) \\ Post Graduate Institute of Medical Education and research,Chandigarh,India
}

\section{Research Article}

Keywords: Adverse events, Medical device adverse event, Materiovigilance, MvPI, Risk classes, Post-marketing surveillance

Posted Date: November 5th, 2021

DOI: https://doi.org/10.21203/rs.3.rs-892194/v1

License: (9) (1) This work is licensed under a Creative Commons Attribution 4.0 International License. Read Full License 


\section{Abstract}

Background: This is the first study to evaluate the pattern of adverse events related to medical devices in India. We aimed to evaluate medical device adverse events (MDAEs) reported at a tertiary level teaching hospital in northern India.

Methods: This descriptive study was conducted ambispectively at PGIMER, Chandigarh. We used the medical device risk classification given by the Indian regulatory authority which was framed in line with the recommendation of the Global Harmonization Task Force. The prospective study (PS) was done from January 2020 to December 2020 with a concurrent retrospective study (RS) proceeding to three years so as to learn more about the reporting culture, demographics, risk class of devices and the type of adverse events.

Result. We obtained $224 \mathrm{MDAE}$ in the prospective study and identified $413 \mathrm{MDAE}$ in retrospective study. Reporting culture of retrospective adverse events to the national materiovigilance programme of India (MvPI) was negligible. Marginally increased incidence of MDAE reported among male patients (PS; $52 \%$, RS; $57 \%$ ) and age group between 21-30 years (PS; $19.1 \%, \mathrm{RS} ; 23.2 \%$ ) in both studies. Fewer number of MDAEs were also reported from infants (7.5\%) and the elderly (6.9\%) population. Regarding risk class, MDAEs were frequent in low to moderate risk devices (Class B: $66 \%$ ) in the prospective study, while it was documented only for high-risk devices (Class C: $51 \%$ \& Class D: $49 \%$ ) in the retrospective study. However, serious adverse events (SAEs) were equally prevalent among moderate to high-risk devices (Class B: 33\%, C: 34\% \&D: 33\%). An increased frequency of SAE was observed among non-notified medical devices (60.4\%). Concerning reporting culture, nurses reported the majority of MDAEs (65\%). Overall $14 \%$ of the incidents were documented as near-miss events.

Conclusion: Medical devices elicit adverse events irrespective of their risk class, notification status and patient demographic factors. Escalated reporting of MDAEs by surgeons and biomedical engineers is recommended at India.

\section{Introduction}

Medical devices (MDs) are an integral part of the health care delivery system and contribute to patient care enormously. However, at certain circumference, they can also lead to adverse events (AEs) or injuries of their users, ranging from non-serious to serious AEs[1]. The medical devices represent "All instruments, apparatus, implant, in vitro reagent, or software intended for disease diagnosis or treatment in humans"[2]. It is estimated that 2 million MDs of various types are available in the global market and a multispecialty hospital uses over 5000 various categories of MDs for day-to-day operations [3]. A recent retrospective study by Porte et al. (2020) reported that medical device adverse events (MDAE) were present in $2.8 \%$ of the admissions in Dutch hospitals[4]. Unlike drugs, the malfunctioning of a single medical device may lead to a community disaster. For example, if a blood pressure monitoring apparatus does not work properly at a community hypertension clinic, it might lead to the unwanted prescription of medication to all OPD attending patients. The following are some real-life incidents of serious adverse events (SAEs) reported from India. A patient received electrical burn injury as a result of defibrillator failure[5], metal ions were found in the blood and soft tissue of patients following hip replacement surgery [6], and a newborn baby died after the overheating of an incubator[7]. The true public health impact of MDAE is unclear and reported cases could be an iceberg of all adverse events[8]. Because it is estimated that as little as $0.5 \%$ of all medical device adverse events were reported to the United States Food and Drug Administration(US-FDA) [9].

The impact of MDAEs varies based on the complexity, intended purpose, and invasive nature of the MDs[10]. Non-invasive and simple medical devices are probable to cause non-serious adverse events while invasive and complex devices are probable to cause serious adverse events(SAE)[11]. An adverse event labeled as SAE, if it is life threatening, requires hospitalization or lead to prolongation of existing hospitalization, or cause disability, congenital abnormality or led to death[12]. The safety of licensed medical devices ensured by implementing post marketing surveillance(PMS)[13]. Even though manufacturers are largely responsible for post-marketing surveillance, regulatory authorities have specific role at various levels[14]. As per WHO health statistics report-2016, sixty five percentage of 145 countries have established regulatory authority for executing PMS[15]. However, the criteria for regulatory framework vary among implemented countries. To bring uniformity in regulatory approval and post-marketing surveillance, the Global Harmonization Task Force (GHTF) classified medical devices into four classes (Class A, B, C, and D) where class A indicate low risk, class B indicate low to moderate risk, class C indicates moderate-high risk, and class D devices present a higher risk to patients[16]. Presently the studies regarding the pattern of MDAE according to GHTF riskbased classification is limited. Since the Government of India adopted the same classification of medical devices given by the GHTF and framed a medical device rule in 2017 (MD rule-2017) [17], the studies from the Indian perspective might be amplifiable to the global perspective. In the United States, the postmarketing surveillance is done by FDA, however, their risk-based classification is different compared to GHTF.

The Central Drug Standard Control Organization-CDSCO) is the regulatory authority responsible for implementing MD rule-2017 and post-marketing surveillance in India. CDSCO launched Materiovigilance Programme of India (MvPI) in July 2015 at Indian Pharmacopoeia Commission (IPC) for employing post-marketing surveillance. The limitation of MD rule-2017 is all medical devices are not amenable to this law. Presently MD rule-2017 is limited to medical devices that are periodically notified by the Government of India. Usually, registration is not required for the import and marketing of non-notified medical devices in India. As of 01/01/2020, only 37 medical devices are notified (Annexure-1) and many medical devices are not included in the notified list. The frequently used non-notified medical devices include oxygen masks, infusion pumps, ventilators, incubators, etc. Previous studies in other countries have shown adverse events including SAE with above devices[18] [19]. However, the magnitude of adverse events caused by these non-notified medical devices is also limited in India. Therefore in the present study, in addition to evaluating the pattern of MDAE according to GHTF risk based classification of medical devices, we also evaluated the notification status of respective medical devices as per MvPI guidelines. Ambispective study was planned to have more insight by comparing reporting culture, demographics, devices frequently caused adverse events, risk class, notification status, and the nature of the adverse events. Furthermore, the knowledge concerning the pattern of MDAE might promote the careful use of medical devices consequently endorse patient safety.

\section{Methods}


This descriptive study was designed as a single-centre ambispective study. Prospective study data collection was done from $1^{\text {st }}$ January-2020 to $31^{\text {st }}$ December 2020 by visiting various medical and surgical departments. A retrospective study was done for a period of 3 years from $1^{\text {st }}$ January 2017 to $31^{\text {st }}$ December 2019 by reviewing patient records kept at the medical record department (MRD) and registries kept in operation theatres. The study was approved by the institutional ethics committee (IEC) of Post Graduate Institute of Medical Education and Research, Chandigarh vide order INT/IFC/2020/SPL$407 / 2020$. Collecting and reporting of medical device adverse events were performed in accordance with the relevant guidelines and regulations given by Materiovigilance Programme of India (MvPI).

\section{Inclusion/Exclusion criteria}

All reported MDAE in hospitalized and OPD attending patients were included irrespective of age, gender, diagnosis, or treatment.

\section{Sample Size}

We had included nearly all the cases of MDAE as per the record and reporting within the timeframe.

\section{MATERIALS}

MDAE reporting form downloaded from www.ipc.gov.in (Annexure-2) was used as case record file and the notification regarding MD released by CDSCO as on 01/01/2020 was followed. (Annexure- 1)

\section{DATA COLLECTION}

We employed active and passive surveillance for data collection. The passive method involved spontaneous targeted reporting in which we conducted an awareness program for doctors, nurses, and technicians regarding MvPI and how to report medical device adverse events in a prescribed form. We took the help of social media and e-mails to remind health care workers to report MDAE. Active surveillance was done by personally visiting various OPDs and IPD departments. Patients using medical devices were screened and documented if any adverse events were observed. For retrospective data collection, screening of registers kept at various OTs and patient case file kept at MRD was done.

\section{Statistical Analysis}

All the data collected during the study period were entered into the master sheet through Microsoft excel software (Microsoft Co. USA). The categorization of data was done both qualitatively and quantitatively as applicable and Poisson distribution was applied. The results were expressed in absolute number and percentage. The correlation between the incidences of serious adverse events with notification status of MDAE was executed with the Chi-square test along with Yates correlation. The p-value $<0.05$ was considered statistically significant.

\section{Results}

In total 637 MDAE were reported retrospectively and prospectively, out of which 413 cases were identified from retrospective study and 224 cases were reported from prospective study. For the retrospective study, we initially screened up to 6250 medical records randomly, but no MDAE were detected. So the screening criteria were then confined to patients who had implantation of any type of medical device. Then we identified 23892 cases having an implant in situ. The hospitalization of these patients with an implant-related problem was taken as a sample. We got a total of 413 patients (Figure 1). Among these nearly half of patients were reported from the orthopaedic dept (Implants: $n=203,49.1 \%)$ followed by Gynaecology dept (Copper T: $n=116,28 \%$ ) and ophthalmology dept (IOL: $n=94,22.9 \%)$. However, in the prospective study, MDAE were reported across all departments through spontaneous reporting. The MDAE pattern was further broken down into various categories given below.

\section{Demographic profile and pattern of MDAE}

A slightly higher incidence of MDAE was reported among male patients in both retrospective (M: $234,57 \%, F: 179,43 \%)$ and prospective studies (M: 100 , $52 \%, F: 92,48 \%)$. Demography was not recorded for near-miss events. To understand the age-wise distribution of MDAE, all patients were divided into nine age groups (Figure 2). The incidence of MDAE was highest among the age group 21-30 years in both retrospective ( $n=96,23.2 \%)$ and prospective studies $(n=43,19.1 \%)$. The mean age of the patients was 41.8 years in retrospective and 33.7 years in the prospective study. About $5 \%$ ( $n=19)$ of MDAE were observed in children (Age<12yr) in the retrospective study compared to $15 \%(n=29)$ in the prospective study. Further, in the prospective study, it was observed that infants $(0-1 \mathrm{yr})$ were also prone to MDAE as $7.5 \%(n=17)$ cases were reported among these cohorts. Nearly $6.9 \%(n=15)$ of elderly people (Age $>65)$ were affected with MDAE. The youngest patient was 3 days old and the eldest was 84 years old.

\section{Medical devices frequently associated with MDAE}

The following medical devices caused frequent MDAE in the prospective study. Personal Protective Equipment ( $n=58,25.8 \%)$ was accounted for a quarter of AE followed by Kojak syringe ( $n=36,16 \%)$ and Infusion/syringe pumps ( $n=33,14.7 \%)$ (Figure 3). We also analyzed whether the medical devices involved in AE relied on any software support for its intended functioning and found $29.46 \%(n=66)$ of medical devices were software-enabled. In terms of near-miss events, $14 \%(n=32)$ of the instances were classified as near-missed events in the prospective study. Further, regarding the invasive status of medical devices, most AEs were associated with non-invasive $(n=200,89.3 \%)$ and single-use $(n=160,71.7 \%)$ devices (Table 1). 


\section{Different classes of medical devices and frequency of MDAE.}

In the prospective study, two-thirds of the AE were caused by low to moderate risk devices (Class B: $n=147,66 \%$ ) while the rest one-third of $A E$ were caused by moderate to high-risk devices. (Class C: $n=55,24 \%$ \& Class D: $n=17,8 \%$ ). (Figure 4). However, in the retrospective study, no adverse events were reported with low to moderate risk devices (Class A\&B), whereas high-risk devices (Class C: $n=210,51 \%$ \& Class D: $n=203,49 \%$ ) were responsible for all MDAEs. A brief description of the adverse event caused by different classes of medical devices is given in Table 1.

\section{Notification status of medical devices and incidence of MDAE.}

Overall, slightly higher incidence of the MDAE was reported in case of notified ( $n=119,53 \%)$ medical devices in the prospective study. But, out of 58 SAE reported, non-notified devices were responsible for more than half of the cases $(n=35,60 \%)$ of SAE (Table 1). However, no significant relation between SAE and non-notified medical devices was found at $p$-value $<0.05$ as the calculated $p$-value was 0.699806 . In the retrospective study, all devices which caused MDAE belonged to the list of notified devices.

\section{Severity of MDAE}

In the prospective study, a quarter of AE were reported as SAE ( $n=58,26 \%)$. Among SAE, life-threatening cases were $32 \%$ ( $n=18)$, prolongation of hospitalization was reported in $34 \%(n=19)$ cases, intervention to prevent further complication was needed in $34 \%$ cases ( $n=19)$ and a few of adverse events resulted in deaths ( $n=2,4 \%$ ) (Figure 5). Concerning the risk class of devices and SAE, Class B caused 33\% ( $n=19)$ SAE, Class C caused $34 \%$ ( $n=20)$ SAE and Class D devices caused 33\% ( $n=22)$ SAE. The incidence of SAE among notified medical devices was 39.6\% ( $n=23)$ whereas among non-notified devices it was $60.4 \%(n=35)$ (Table 1). Software-supported devices accounted for $36.84 \%$ of all SAEs. In the retrospective study, all MDAE were reported as SAE since they needed hospitalization.

\section{Adverse events reported by distinct healthcare professionals.}

Nurses reported most of the AEs (65\%) while doctors reported only $30 \%$ of AE. Reporting by medical technical staff ( $2 \%$ ) and other healthcare workers ( $3 \%$ ) were very few. However, MDAE reported by biomedical engineers was negligible. (Figure 6)

\section{Discussion}

The present study is the first of its kind, to evaluate the pattern of medical device adverse events according to GHTF risk classification of MD as well as to highlight the nature of adverse events concerning to notification status of MD followed in India.

We received 224 MDAE in the prospective study and identified 413 MDAE in the retrospective study. Since the retrospective analysis was performed for a three-year (2017-2019) period and the prospective study was performed for a one-year (2019) period, the discrepancy in cumulative counts might have occurred. But, none of the MDAEs that happened during the retrospective study period were reported to the same hospital's functional MvPI centre. The number of MDAE in our prospective study was lower than a previous study by Samore MH et al(2004), who detected 552 MDAE over 9 months [19]. However, their study was based on computer-flag-based surveillance while our study was based on spontaneous reporting approach. In our prospective study, we identified low to moderate risk devices (Class B) as being responsible for the majority (66\%) of adverse events, followed by moderate to high risk (Class $C, 24 \%$ ) and high risk (Class D,8\%) devices. But, in our retrospective study, it was found that class C\& D devices were associated with all the adverse events. The disparity may be due to the adverse event by Class B devices which are not commonly recorded in patient's case files and nurses reported most of MDAE in the prospective study (65\%).

We found that the majority (74\%) of MDAE were non-serious, while a quarter (26\%) resulted in serious consequences, including death. But these findings were inconsistent with the MvPI study, which indicate that majority (66.1\%) of reported cases to MvPI were serious adverse events. This may be due to stakeholder's preference to report merely serious adverse events to MvPI. Further, the incidences of SAEs were equally prevalent among Class B (33\%), C (34\%) \& D (33\%) devices and higher in non-notified (60.4\%) medical devices. So we recommend bringing all the devices under the purview of the notified list, irrespective of risk class as early as possible.

In the prospective study, the devices associated with frequent MDAE were PPE kits (25.89\%), followed by Kojak syringe (16.07 \%) and infusion pumps (14.73\%). Since the prospective study was conducted during the Covid-19 pandemic there is an increased reporting of AE associated with PPE. Furthermore, AE correlated with PPE have a significant impact on the health of health care professionals, and their experience of monitoring and reporting MDAE may have contributed to increased reporting of AE with PPE. This coincidental result indicates that improved recognition of medical device adverse events by recipients (patients) would aid in the early detection and reporting of MDAE. A study by Kavanagh et al (2019) found patients and their relatives were the most frequent submitter of reports directly to the US FDA manufacturer and user facility device experience (MAUDE) database[20]. So, Indian regulatory agencies should extend post-marketing monitoring to recipients (patients) rather than limiting it to healthcare professionals. Another study by Samore et $\mathrm{al}(2004)$ found foleys catheters (57\%) and arterial catheters were the devices most commonly associated with MDAE in their study[19]. However, in the present study, no cases with these devices were reported. But a study by Gagliardi et al(2017) showed that infusion pumps are the most common device associated with priority 1 recall in Canada[21]. Conversely to prospective study, in the retrospective study, it was found that orthopaedic implants were responsible for almost half (49.1\%) of the adverse events followed by Copper T (28 \%) and then by Intra Ocular Lenses (22.9\%). However, no adverse events associated with these devices were reported during the prospective study period. Since adverse events associated with these devices are primarily detected 
by treating clinicians, especially by surgeons, there is an urgent need to promote MDAE reporting behaviour among surgeons in our country. And also the pattern of MDAE will be influenced by which professional category reports more MDAE.

All the patients who have been exposed to medical devices, regardless of age or gender, are at risk for MDAE, since we found the incidence of MDAE in adults (85\%) including the elderly population (6.9\%) and children (15\%) including infants (7.5\%). The age group of 21 to 30 years has the highest prevalence of MDAE in both retrospective (23.2\%) and prospective studies (19.1\%). Male patients outnumbered females in both studies. (RS: $M=52 \%, F=48 \%$. $P S$ : $M=57 \%$, $\mathrm{F}=43 \%$ ). But this finding is contradictory to the findings of Peterson et al, who reported female patients are more likely than men to have procedure-related adverse events in-hospital[22]. The male sex predominance in our study may be attributed to the fact that the majority of admitted patients were male. The mean age of the patient population in the retrospective study was 41.8 years, while the mean age in the prospective study was 33.7 years.

The overall incidence of near-miss adverse events was $14 \%$. Near-miss adverse events mean a patient is exposed to a potentially dangerous scenario but is spared from injury due to chance or early identification by the reporter. Further, most of the adverse events were reported among non-invasive devices (89\%). So the regulators need to ensure the quality and safety of non-invasive material as well.

In this study, nurses reported the majority of adverse effects (65\%), followed by doctors, a few by OT technicians and negligible reporting from biomedical engineers. A study by Kavanagh et al also found nurses report MDAE 2.77 times more often than doctors directly to the US FDA-MAUDE [20]. Another study by Shamim et al(2016), was also of the same opinion where the reporting of $A E$ was found significantly more among nurses $(P=0.006)[23]$. However, a study conducted by Alsohime et al(2019), among ICU nurses in Saudi Arabia found that even though $66 \%$ of nurses experienced medical device adverse events, only $2 \%$ of nurses reported it correctly to the existing national reporting system[24]. Therefore there are chances that the adverse events reported in this study might be an iceberg of the total medical device adverse events that originally occur. Currently, in the United States, it is mandatory for the manufacturers to report, while health providers can report voluntarily. In Spain, health care workers must report MDAE.

The present study also identified that more than one-third of (36.84\%) SAE were caused by software-supported medical devices. A previous study by Gagliardi et al (2017) reported that software-supported medical devices (Laboratory software, diagnostic software, patient management software) caused recalls including priority-1 [21]. Therefore a separate surveillance system for software used in the health care field is a need of the hour.

\section{Conclusion}

Medical device adverse event (MDAE) can be potentially life-threatening, prolong hospitalization, or can even lead to death if not intervened promptly. Although this study provides a peripheral view of adverse events caused by the medical devices, it highlights the necessity of mandatory reporting by health care professionals especially by surgeons and biomedical engineers. Most of the adverse events were reported in case of Class B (low to moderate risk) risk devices. The incidence of serious adverse events (SAE) was equally prevalent among class B (33\%), C (34\%) \& class D (33\%) devices and an increased frequency of SAE was observed among non-notified (60.4\%) medical devices. The pattern of MDAE was heavily influenced by the professional category that reported more MDAE. This study warrants further research for the development of possible intervention strategies to reduce the burden of MDAE such as keeping an implant registry, and assessment of the economic impact of MDAE. We intend to continue our research by assessing the causality and preventability of medical device adverse events.

\section{Limitation Of The Study}

Overall, the present study was limited to the adverse event finding in case of notified and non-notified bed side medical devices and not focused on In-vitro Diagnostic devices (IVD). The root cause analysis of reported adverse events was not performed widely. The healthcare workers need constant motivation and education through the CMEs or materiovigilance meetings, social media messages to increase the amount of spontaneous reporting. There is a need for systematic reporting and evaluation of MDAE for the safety of the general population.

\section{Declarations}

\section{Conflict of interest}

The authors declare that there is no conflict of interest.

\section{Ethics approval and consent to participate}

The present study was approved by Institutional Ethics Committee (IEC) of Post Graduate Institute of Medical Education and Research (PGIMER), Chandigarh vide order no INT/IFC/2020/SPL-407/2020. Collecting and reporting of medical device adverse events were performed as per ICMR (Indian Council for Medical Research) guidelines for biomedical research Oct-2017 and GCP (Good Clinical Practice) established by CDSCO (Central Drug Standard Control Organization) under Drug \& Cosmetic Act 1940. As per Materiovigilance Programme of India (MvPI), health care workers needed to report medical device adverse events voluntarily and informed consent from patient is not mandatory to report medical device adverse events as it does not collect the name of patients and not disclose the identity of the patients. So informed consents were not obtained from the patients. The IEC of Post Graduate Institute of Medical Education and Research (PGIMER), Chandigarh approved this study after the declaration of the author that confidentiality of each patient will be maintained. Prior to commencement of study we have educated health care workers regarding MvPI and their responsibility of voluntarily reporting medical device adverse events. Further health care workers were informed that the data provided by them will be utilized for basic studies to strengthen MvPI which is a secondary objective of MvPI. 


\section{Consent for publication}

The author gives their full approval for publication.

\section{Availability of data and materials}

The datasets used and/or analysed during the current study are available from the corresponding author on reasonable request.

\section{Competing interests}

The authors declares that they have no competing interests

\section{Funding}

No funding was received for this study

\section{Authors' contributions}

PK, AP\& BM designed the study. RS, SK, VS, RMK, SS, PS provided the resources and data. PK, AP, BM \& PS analysed, interpreted and discussed the data. PK\&AP drafted the article. All authors reviewed and revised the article critically for important intellectual content.

\section{Acknowledgements}

Mr Mukesh Kumar, Ex-materiovigilance research associates PGIMER, Chandigarh. Sukhmeet Kaur, Editorial Assistant-Experimental pharmacology laboratory, PGIMER, Chandigarh. Saniya Mahendiratta, PhD Scholar

Conflict of interest: The authors declare that there is no conflict of interest.

Financial disclosure: No funding was received for this study

\section{References}

1. Amoore J, Ingram P. Learning from adverse incidents involving medical devices. BMJ. 2002;325:272-5.

2. Affairs 0 of R. Medical Device Overview. FDA. 2019. https://www.fda.gov/industry/regulated-products/medical-device-overview. Accessed 15 Jul 2021.

3. Medical devices. https://www.who.int/westernpacific/health-topics/medical-devices. Accessed 20 Jul 2021.

4. Porte PJ, Smits M, Verweij LM, de Bruijne MC. The Incidence and Nature of Adverse Medical Device Events in Dutch Hospitals: A Retrospective Patient Record Review Study. 2020;00:7.

5. Meher BR. Materiovigilance: An Indian perspective. Perspect Clin Res. 2018;9:175-8.

6. How Johnson and Johnson hip implants system went wrong. The Indian Express. 2020. https://indianexpress.com/article/explained/johnson-andjohnson-how-hip-implants-went-wrong-jp-nada-5331779/. Accessed 19 Mar 2021.

7. Banerjee S. New-born baby charred to death in Pune hospital after incubator overheats. The Hindu. 2017. https://www.thehindu.com/news/national/other-states/newborn-charred-to-death-in-pune-hospital-after-incubator-overheats/article19762120.ece. Accessed 19 Mar 2021

8. Hefflin BJ, Gross TP, Schroeder TJ. Estimates of medical device-associated adverse events from emergency departments. American Journal of Preventive Medicine. 2004;27:246-53.

9. Resnic FS, Normand S-LT. Postmarketing Surveillance of Medical Devices - Filling in the Gaps. https://doi.org/10.1056/NEJMp1114865. 2012. doi:10.1056/NEJMp1114865.

10. Aronson JK, Heneghan C, Ferner RE. Medical Devices: Definition, Classification, and Regulatory Implications. Drug Saf. 2020;43:83-93.

11. Lalis G. Title: Principles of Medical Devices Classification :GHTF. 2006;:27.

12. Tietje C, Brouder A, editors. International Conference On Harmonisation Of Technical Requirements For Registration Of Pharmaceuticals For Human Use. In: Handbook of Transnational Economic Governance Regimes. Brill | Nijhoff; 2010. p. 1041-53. doi:10.1163/ej.9789004163300.i-1081.897.

13. Randall H. Post-marketing surveillance and vigilance for medical devices: the European approach. Drug Saf. 2001;24:869-72.

14. Guidance for post-market surveillance and market surveillance of medical devices, including in vitro diagnostics. https://www.who.int/publicationsdetail-redirect/9789240015319. Accessed 20 Aug 2021.

15. WHO Country Cooperation Strategy 2016-2020: Brazzaville; 2016. https://apps.who.int/iris/handle/10665/255018. Accessed 9 Sep 2021.

16. GHTF Study Group 1 - Pre-market Evaluation. http://www.imdrf.org/documents/doc-ghtf-sg1.asp. Accessed 24 Jul 2021.

17. Classificationg1.pdf. https://cdsco.gov.in/opencms/export/sites/CDSCO_WEB/Pdf-documents/medical-device/Classificationg1.pdf. Accessed 24 Jul 2021.

18. Gao X, Wen Q, Duan X, Jin W, Tang X, Zhong L, et al. A Hazard Analysis of Class I Recalls of Infusion Pumps. JMIR Hum Factors. 2019;6. doi:10.2196/10366.

19. Samore MH. Surveillance of Medical Device-Related Hazards and Adverse Events in Hospitalized Patients. JAMA. 2004;291:325. 
20. Kavanagh KT, Brown RE, Kraman SS, Calderon LE, Kavanagh SP. Reporter's occupation and source of adverse device event reports contained in the FDA's MAUDE database. Patient Relat Outcome Meas. 2019;10:205-8.

21. Gagliardi AR, Takata J, Ducey A, Lehoux P, Ross S, Trbovich PL, et al. MEDICAL DEVICE RECALLS IN CANADA FROM 2005 TO 2015 . Int J Technol Assess Health Care. 2017;33:708-14.

22. Peterson Pamela N., Daugherty Stacie L., Wang Yongfei, Vidaillet Humberto J., Heidenreich Paul A., Curtis Jeptha P., et al. Gender Differences in Procedure-Related Adverse Events in Patients Receiving Implantable Cardioverter-Defibrillator Therapy. Circulation. 2009;119:1078-84.

23. Shamim S, Sharib SM, Malhi SM, Muntaha S, Raza H, Ata S, et al. Adverse drug reactions (ADRS) reporting: awareness and reasons of under-reporting among health care professionals, a challenge for pharmacists. Springerplus. 2016;5. doi:10.1186/s40064-016-3337-4.

24. Alsohime F, Temsah M-H, Hasan G, Al-Eyadhy A, Gulman S, Issa H, et al. Reporting adverse events related to medical devices: A single center experience from a tertiary academic hospital. PLOS ONE. 2019;14:e0224233.

\section{Tables}

Table 1: Brief description of adverse event caused by different class of medical devices. 


\begin{tabular}{|c|c|c|c|c|c|c|c|c|}
\hline $\begin{array}{l}\text { Device risk } \\
\text { class }\end{array}$ & Medical Device & $\begin{array}{l}\text { Number of } \\
\text { MDAE }\end{array}$ & $\begin{array}{l}\text { Notification } \\
\text { status of } \\
\text { MD }\end{array}$ & $\begin{array}{l}\text { Invasive } \\
\text { status } \\
\text { of MD }\end{array}$ & $\begin{array}{l}\text { Usage } \\
\text { Practice }\end{array}$ & $\begin{array}{l}\text { Software/Programme } \\
\text { enabled device }\end{array}$ & Adverse Event & $\begin{array}{l}\text { Severity of } \\
\mathrm{AE}\end{array}$ \\
\hline \multirow[t]{2}{*}{$\begin{array}{l}\text { Class } \\
\text { A (Low } \\
\text { risk) }\end{array}$} & Hygienic soap & $\begin{array}{l}2 \\
(P S=2 \& R S=0)\end{array}$ & Notified & $\begin{array}{l}\text { Non } \\
\text { invasive }\end{array}$ & Single use & No & Hypersensitivity & $\begin{array}{l}\text { Non } \\
\text { Serious=2 } \\
S A E=0\end{array}$ \\
\hline & Electronic bed & $\begin{array}{l}3 \\
(P S=3 \& R S=0)\end{array}$ & Notified & $\begin{array}{l}\text { Non } \\
\text { invasive }\end{array}$ & Reusable & No & $\begin{array}{l}\text { Exacerbation of } \\
\text { breathing difficulty, } \\
\text { Malfunction }\end{array}$ & $\begin{array}{l}\text { Non } \\
\text { Serious=3 } \\
S A E=0\end{array}$ \\
\hline \multirow{8}{*}{$\begin{array}{l}\text { Class B } \\
\text { (Low-to- } \\
\text { moderate } \\
\text { risk) }\end{array}$} & Kojak syringe & $\begin{array}{l}36 \\
(P S=36 \& R S=0\end{array}$ & Notified & $\begin{array}{l}\text { Non } \\
\text { invasive }\end{array}$ & Single use & No & $\begin{array}{l}\text { Problem with } \\
\text { diluting and } \\
\text { titration for small } \\
\text { dose, Wastage of } \\
\text { medicine due to } \\
\text { plunger breaking } \\
\text { while loading } \\
\text { medicine, Leak, } \\
\text { Broken syringe, } \\
\text { Quality defect, } \\
\text { Difficulty in } \\
\text { withdrawing } \\
\text { samples. }\end{array}$ & $\begin{array}{l}\text { Non } \\
\text { Serious }=36 \\
S A E=0\end{array}$ \\
\hline & Infusion set & $\begin{array}{l}30 \\
(P S=30 \& R S=0)\end{array}$ & Notified & $\begin{array}{l}\text { Non } \\
\text { invasive }\end{array}$ & Single use & No & $\begin{array}{l}\text { Material quality, } \\
\text { Kinking, Twisting, } \\
\text { Decreased flow } \\
\text { rate. }\end{array}$ & $\begin{array}{l}\text { Non } \\
\text { Serious }=30 \\
S A E=0\end{array}$ \\
\hline & $\begin{array}{l}\text { Blood } \\
\text { transfusion set }\end{array}$ & $\begin{array}{l}10 \\
(P S=10 \& \\
R S=0)\end{array}$ & Notified & $\begin{array}{l}\text { Non } \\
\text { invasive }\end{array}$ & Single use & No & $\begin{array}{l}\text { Leakage of } \\
\text { chamber }\end{array}$ & $\begin{array}{l}\text { Non } \\
\text { Serious=9 } \\
S A E=1\end{array}$ \\
\hline & $\begin{array}{l}\text { Endo tracheal } \\
\text { tube }\end{array}$ & $\begin{array}{l}4 \\
(P S=4 \& R S=0)\end{array}$ & Notified & Invasive & Single use & No & $\begin{array}{l}\text { Injury to } \\
\text { oropharynx due to } \\
\text { high hardness. } \\
\text { Failed cuff } \\
\text { inflation. }\end{array}$ & $\begin{array}{l}\text { Non } \\
\text { Serious=4 } \\
\text { SAE }=0\end{array}$ \\
\hline & Ryles tube & $\begin{array}{l}2 \\
(P S=2 \& R S=0)\end{array}$ & Notified & Invasive & Single use & No & Leakage & $\begin{array}{l}\text { Non } \\
\text { Serious=2 } \\
S A E=0\end{array}$ \\
\hline & IV cannula & $\begin{array}{l}7 \\
(P S=7 \& R S=0)\end{array}$ & Notified & Invasive & Single use & No & $\begin{array}{l}\text { Thrombohlebitis, } \\
\text { leakage }\end{array}$ & $\begin{array}{l}\text { Non } \\
\text { Serious=6 } \\
S A E=1\end{array}$ \\
\hline & $\begin{array}{l}\text { Personal } \\
\text { Protective } \\
\text { Equipment(N- } \\
95 \text { mask, } \\
\text { Gown,Cap,Face } \\
\text { shield) }\end{array}$ & $\begin{array}{l}58 \\
(P S=58 \& R S=0)\end{array}$ & $\begin{array}{l}\text { Non } \\
\text { Notified }\end{array}$ & $\begin{array}{l}\text { Non } \\
\text { invasive }\end{array}$ & Single use & No & $\begin{array}{l}\text { Quality defect, } \\
\text { Suffocation, Tear. } \\
\text { Profuse sweating. } \\
\text { Syncope. Allergy, } \\
\text { Skin mark, } \\
\text { Hyperpigmentation, } \\
\text { Fogging, Pus } \\
\text { formation over } \\
\text { nasal bridge. Injury } \\
\text { to eyelid by metal } \\
\text { rod on nose clip of } \\
\text { mask. } \\
\text { Exacerbation of } \\
\text { Acne }\end{array}$ & $\begin{array}{l}\text { Non } \\
\text { Serious=39 } \\
S A E=17\end{array}$ \\
\hline & $\begin{array}{l}\text { Infusion \& } \\
\text { syringe pump }\end{array}$ & $\begin{array}{l}33 \\
(P S=33 \& R S=0)\end{array}$ & $\begin{array}{l}\text { Non } \\
\text { Notified }\end{array}$ & $\begin{array}{l}\text { Non } \\
\text { invasive }\end{array}$ & Reusable & Yes & $\begin{array}{l}\text { Battery backup } \\
\text { Failure, Delayed } \\
\text { completion of } \\
\text { infusion. Bolus } \\
\text { infusion when } \\
\text { programmed over } 1 \\
\text { hour. False alarm. }\end{array}$ & $\begin{array}{l}\text { Non } \\
\text { Serious }=25 \\
\text { SAE }=8\end{array}$ \\
\hline
\end{tabular}




\begin{tabular}{|c|c|c|c|c|c|c|c|c|}
\hline \multirow[t]{7}{*}{$\begin{array}{l}\text { Class C } \\
\text { (Moderate- } \\
\text { to-high } \\
\text { risk) }\end{array}$} & Ventilator & $\begin{array}{l}12 \\
(P S=12 \& R S=0)\end{array}$ & $\begin{array}{l}\text { Non } \\
\text { Notified }\end{array}$ & $\begin{array}{l}\text { Non } \\
\text { invasive }\end{array}$ & Reusable & Yes & $\begin{array}{l}\text { Ventilator } \\
\text { associated } \\
\text { pneumonia. } \\
\text { Sudden halt of } \\
\text { working. Humidifier } \\
\text { malfunction. } \\
\text { Over delivery \& } \\
\text { under delivery of } \\
\text { programmed FiO2. }\end{array}$ & $\begin{array}{l}\text { Non } \\
\text { Serious }=4 \\
\text { SAE }=8\end{array}$ \\
\hline & $\begin{array}{l}\text { Cardiac } \\
\text { monitor }\end{array}$ & $\begin{array}{l}3 \\
(P S=3 \& R S=0)\end{array}$ & Notified & $\begin{array}{l}\text { Non } \\
\text { invasive }\end{array}$ & Reusable & Yes & $\begin{array}{l}\text { Battery backup } \\
\text { failure. Improper } \\
\text { ECG waves }\end{array}$ & $\begin{array}{l}\text { Non } \\
\text { Serious=3 } \\
\text { SAE }=0\end{array}$ \\
\hline & $\begin{array}{l}\text { Radiant } \\
\text { warmer }\end{array}$ & $\begin{array}{l}1 \\
(P S=1 \& R S=0)\end{array}$ & $\begin{array}{l}\text { Non } \\
\text { Notified }\end{array}$ & $\begin{array}{l}\text { Non } \\
\text { invasive }\end{array}$ & Reusable & Yes & Overheating & $\begin{array}{l}\text { Non } \\
\text { Serious }=0 \\
\text { SAE }=1\end{array}$ \\
\hline & $\begin{array}{l}\text { Blood glucose } \\
\text { monitor }\end{array}$ & $\begin{array}{l}4 \\
(P S=4 \& R S=0)\end{array}$ & Notified & $\begin{array}{l}\text { Non } \\
\text { invasive }\end{array}$ & Reusable & Yes & $\begin{array}{l}\text { Wrong reading } \\
\text { (Cross checked) }\end{array}$ & $\begin{array}{l}\text { Non } \\
\text { Serious=3 } \\
\text { SAE }=1\end{array}$ \\
\hline & $\begin{array}{l}\text { Pulse } \\
\text { Oximeter }\end{array}$ & $\begin{array}{l}1 \\
(P S=1 \& R S=0)\end{array}$ & $\begin{array}{l}\text { Non } \\
\text { Notified }\end{array}$ & $\begin{array}{l}\text { Non } \\
\text { invasive }\end{array}$ & Reusable & Yes & $\begin{array}{l}\text { Wrong reading } \\
\text { (Cross checked) }\end{array}$ & $\begin{array}{l}\text { Non } \\
\text { Serious }=0 \\
\text { SAE }=1\end{array}$ \\
\hline & Defibrillator & $\begin{array}{l}1 \\
(P S=1 \& R S=0)\end{array}$ & Notified & $\begin{array}{l}\text { Non } \\
\text { invasive }\end{array}$ & Resusable & Yes & $\begin{array}{l}\text { Backup failure } \\
\text { during operation. }\end{array}$ & $\begin{array}{l}\text { Non } \\
\text { Serious=0 } \\
\text { SAE }=1\end{array}$ \\
\hline & Copper T & $\begin{array}{l}116 \\
(P S=0 \& R S=116)\end{array}$ & Notified & Invasive & Single use & No & $\begin{array}{l}\text { Pain, Bleeding, } \\
\text { Infection. Thread } \\
\text { missing, Failure }\end{array}$ & $\begin{array}{l}\text { Non } \\
\text { Serious }=0 \\
\text { SAE }=116\end{array}$ \\
\hline \multirow{5}{*}{$\begin{array}{l}\text { Class D } \\
\text { (High risk } \\
\text { devices) }\end{array}$} & $\begin{array}{l}\text { Absorbable } \\
\text { surgical suture }\end{array}$ & $\begin{array}{l}1 \\
(P S=1 \& R S=0)\end{array}$ & Notified & Invasive & Single use & No & $\begin{array}{l}\text { Break of suture } \\
\text { material during } \\
\text { suturing }\end{array}$ & $\begin{array}{l}\text { Non } \\
\text { Serious }=0 \\
\text { SAE }=1\end{array}$ \\
\hline & Pacemaker & $\begin{array}{l}12 \\
(P S=12 \& R S=0)\end{array}$ & Notified & Invasive & Single use & Yes & $\begin{array}{l}\text { Pacemaker site } \\
\text { infection. } \\
\text { Endocarditis, } \\
\text { Battery failure, } \\
\text { Lead infection. }\end{array}$ & $\begin{array}{l}\text { Non } \\
\text { Serious=0 } \\
\text { SAE }=12\end{array}$ \\
\hline & $\begin{array}{l}\text { Orthopaedic } \\
\text { implants }\end{array}$ & $\begin{array}{l}207 \\
(P S=4 \& R S=203)\end{array}$ & Notified & Invasive & Single use & No & $\begin{array}{l}\text { Broken implant. } \\
\text { Pain and restriction } \\
\text { flexion movement. } \\
\text { Implant site } \\
\text { infection. } \\
\text { Malunion. Implant } \\
\text { fatigue, Non-union. } \\
\text { Loosening }\end{array}$ & $\begin{array}{l}\text { Non } \\
\text { Serious }=0 \\
\text { SAE }=207\end{array}$ \\
\hline & IOL & $\begin{array}{l}94 \\
(P S=0 \& R S=94)\end{array}$ & Notified & Invasive & Single use & No & $\begin{array}{l}\text { Lens drop, } \\
\text { subluxated } \\
\text { IOL dislocated } \\
\text { IOL, decentered } \\
\text { IOL, emulsified IOL }\end{array}$ & $\begin{array}{l}\text { Non } \\
\text { Serious }=0 \\
\text { SAE }=94\end{array}$ \\
\hline & Coronary stent & $\begin{array}{l}2 \\
(P S=2 \& R S=0)\end{array}$ & Notified & Invasive & Single use & No & $\begin{array}{l}\text { Stent thrombosis } \\
\text { and death. Chronic } \\
\text { dissection flap } \\
\text { proximal to } \\
\text { coronary stent }\end{array}$ & $\begin{array}{l}\text { Non } \\
\text { Serious }=0 \\
\text { SAE }=2\end{array}$ \\
\hline
\end{tabular}


MDAE: Medical Device Adverse Event.

\section{PS: Prospective Study.}

RS: Retrospective Study.

\section{Figures}

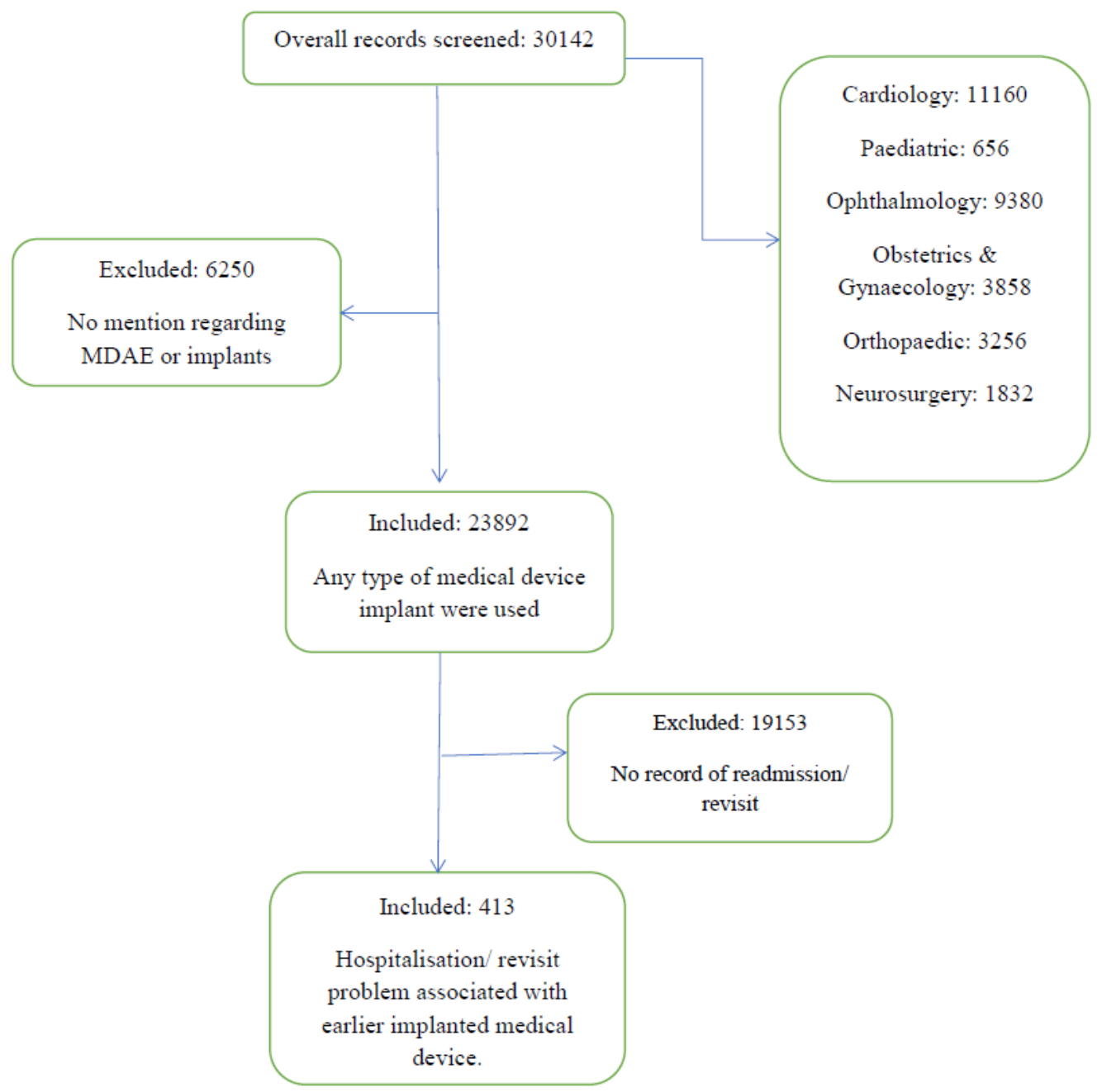

Figure 1

A depiction of retrospective data screening 


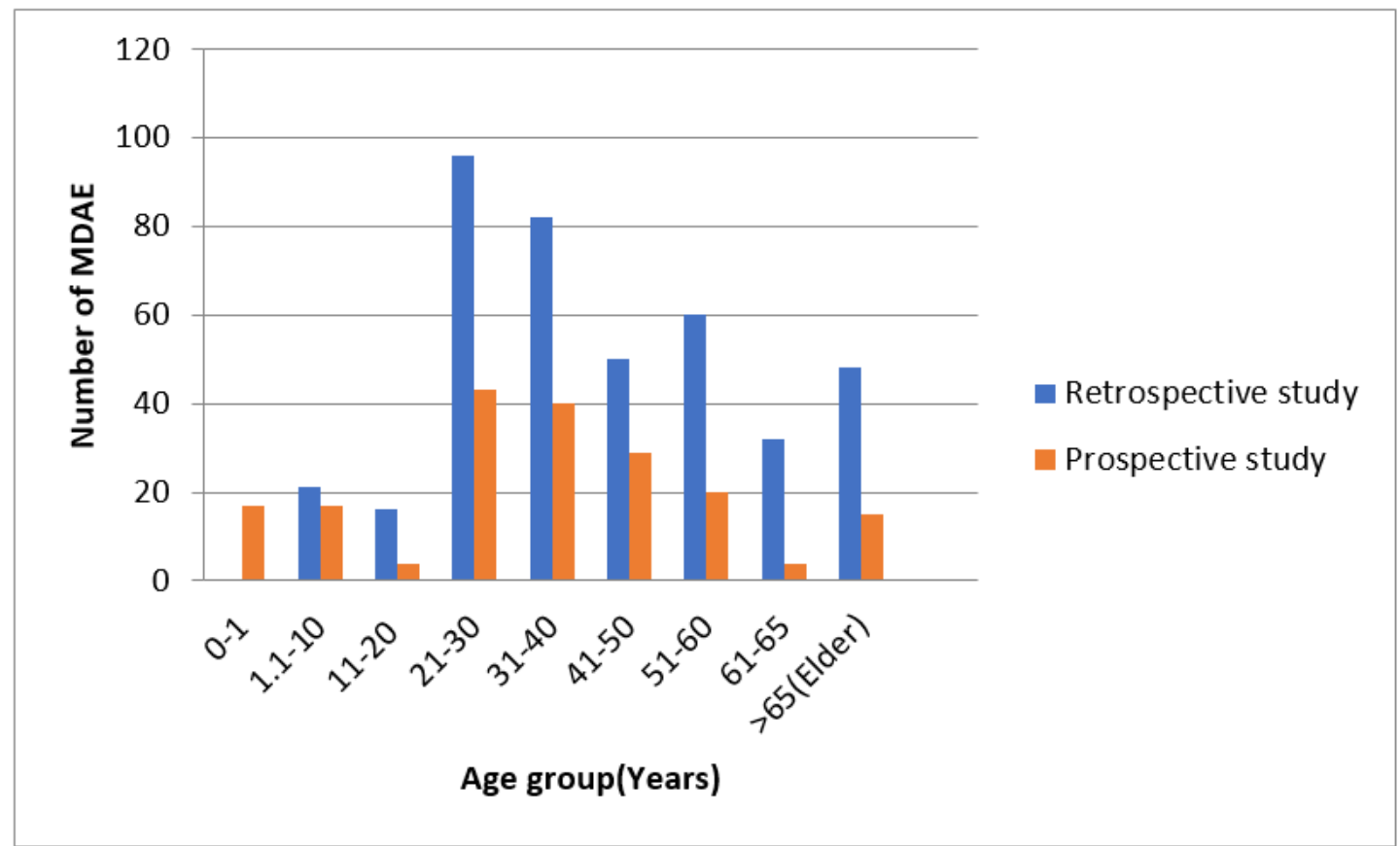

Figure 2

Age-wise distribution of patients with MDAE in retrospective and prospective study

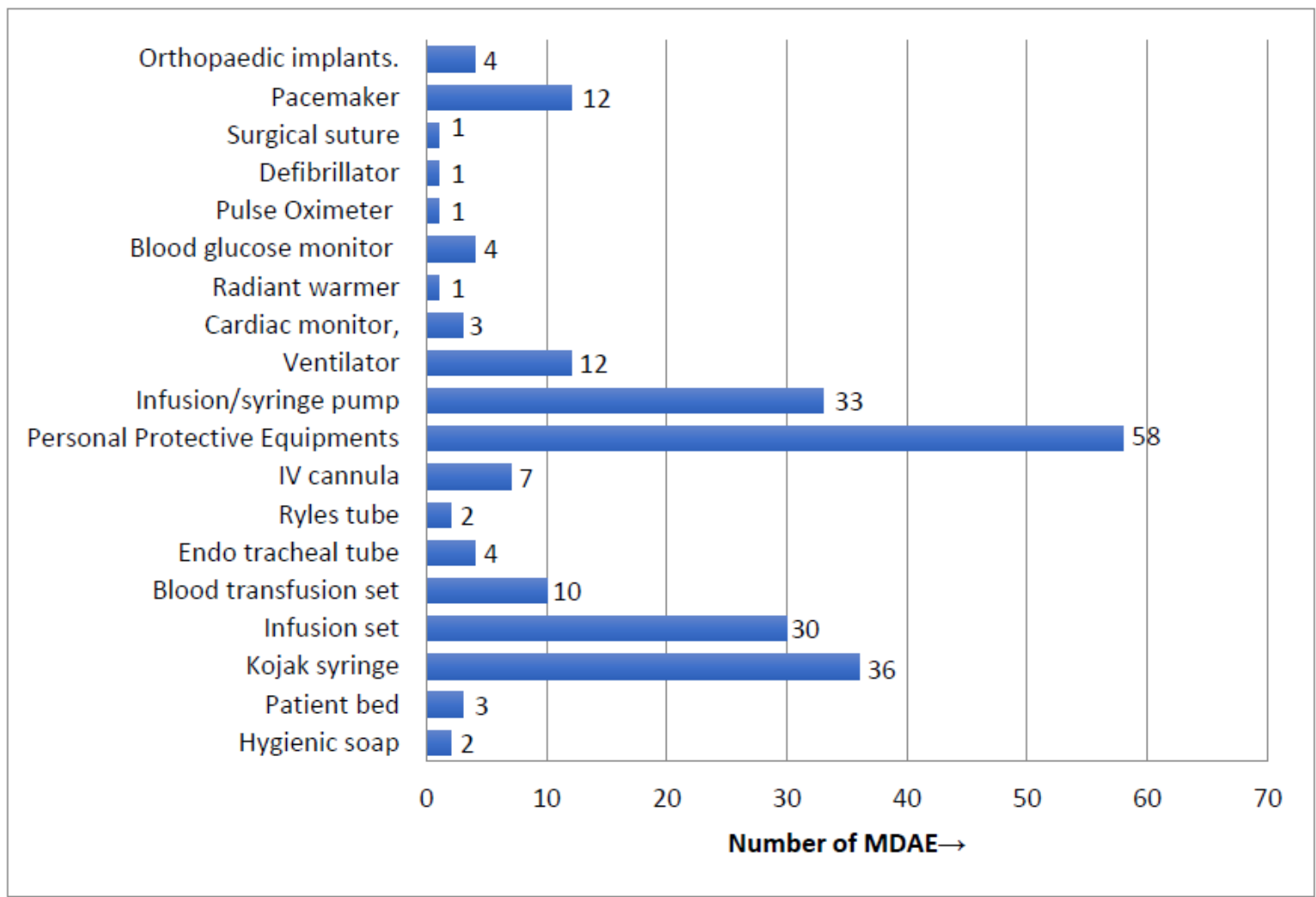

\section{Figure 3}

Medical devices associated with frequent adverse events in the prospective study 


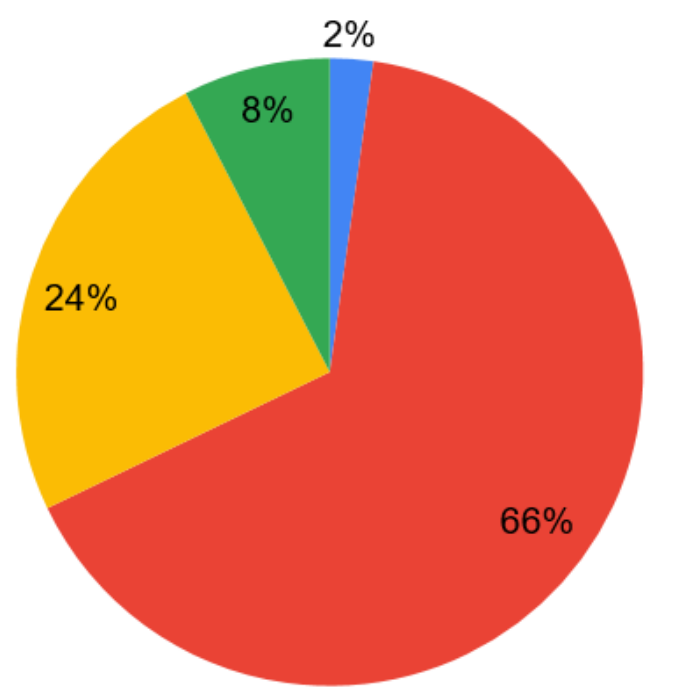

$\square \mathrm{A}$

- $\mathrm{B}$

$\square \mathrm{C}$

- D

\section{Figure 4}

Class wise distribution of MDAE in the prospective study A: Low risk, B: Low to moderate risk, C: Moderate to high risk, D: High risk

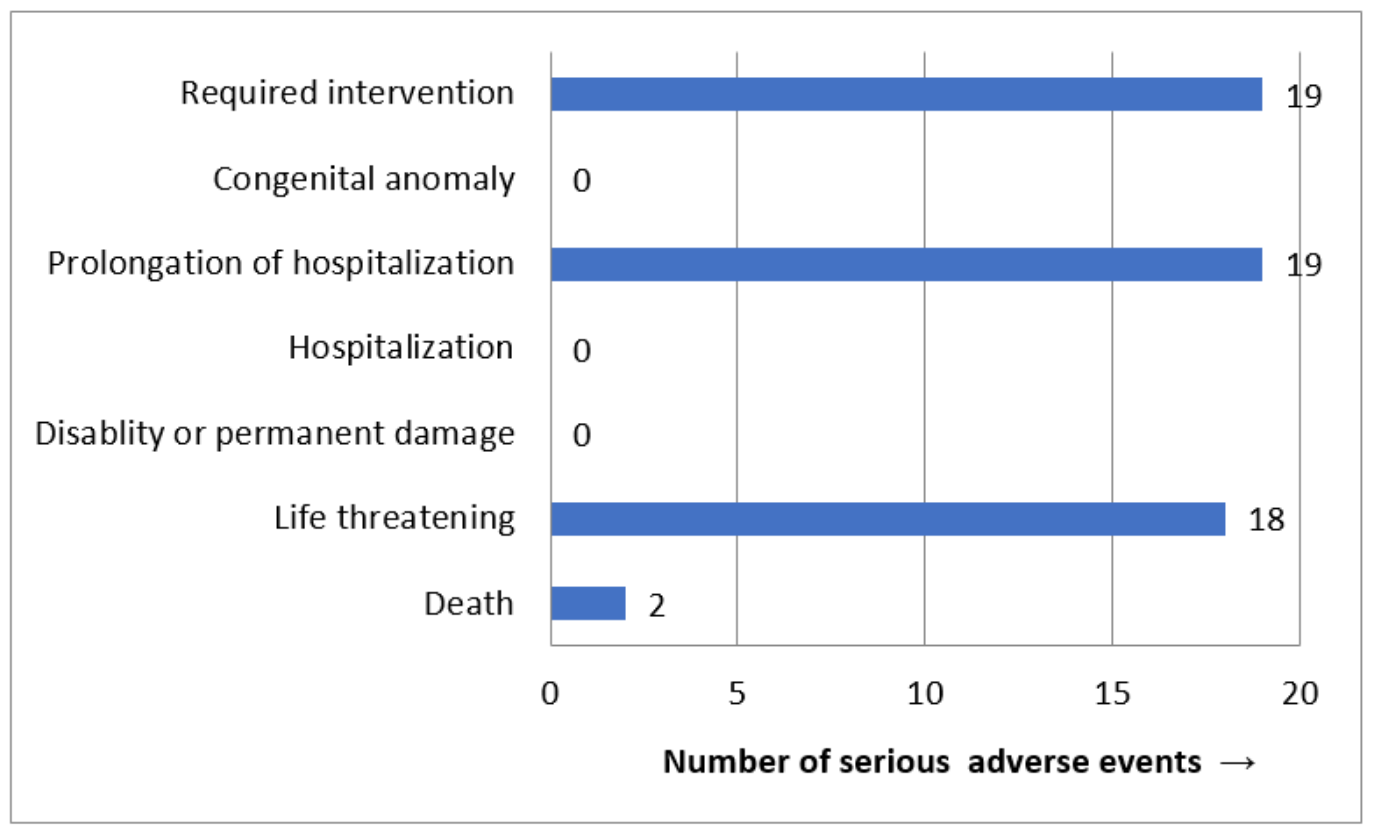

Figure 5

Nature of serious adverse event in prospective study 


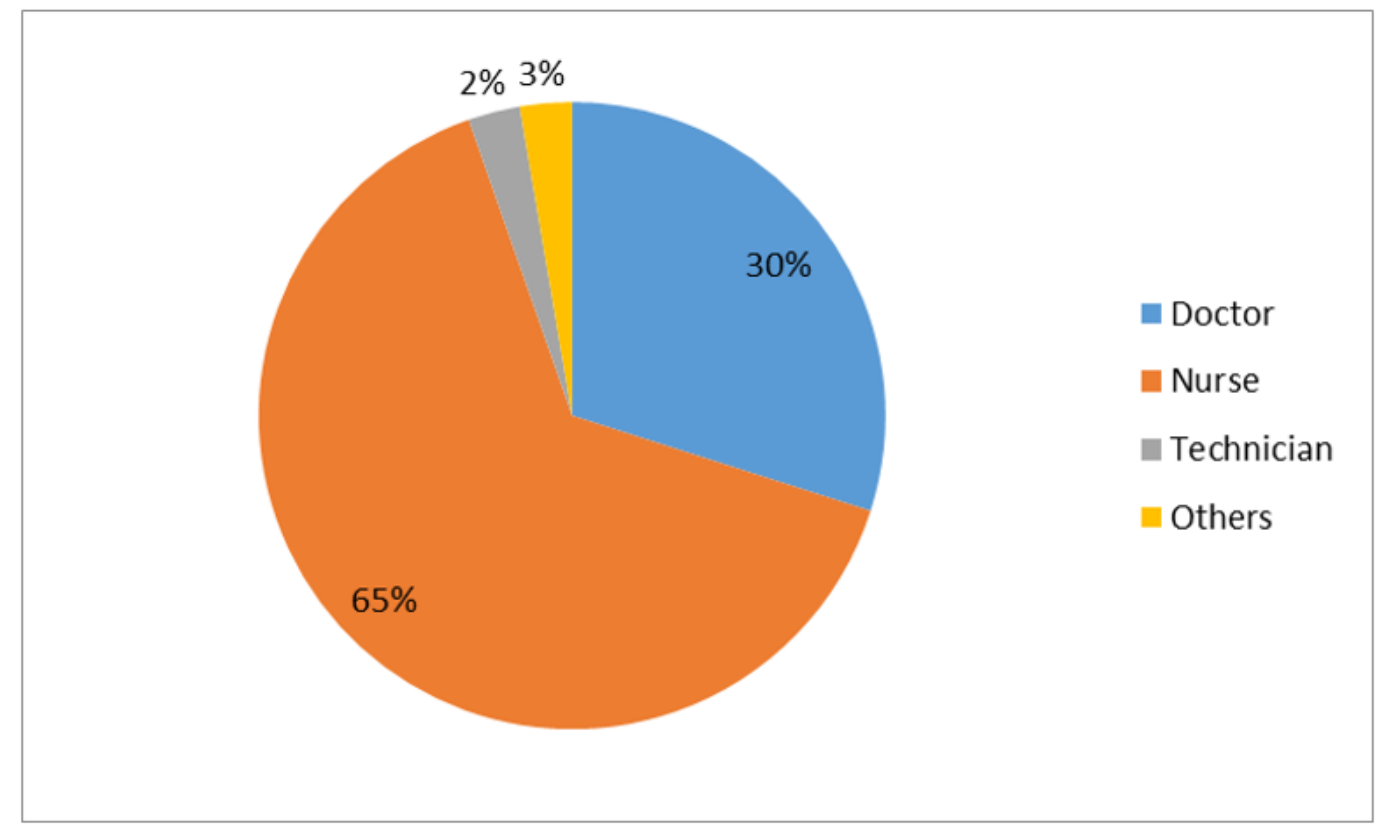

Figure 6

Categories of health care professionals reported MDAE in prospective study

\section{Supplementary Files}

This is a list of supplementary files associated with this preprint. Click to download.

- Annuxure1.NotifiedlistofmedicaldevicesIndia.docx

- Annuxure2MEDICALDEVICEADVERSEEVENTREPORTINGFORM.pdf 